Brit. J. industr. Med., 1960, 17, 209.

\title{
A SIMPLIFIED METHOD FOR THE ESTIMATION OF NICKEL IN URINE
}

\author{
BY \\ J. GWYNNE MORGAN \\ From the Mond Nickel Company Ltd., Clydach, Swansea
}

(RECEIVED FOR PUBLICATION APRIL 15, 1959)

\begin{abstract}
A simplification of Sandell's method for estimating nickel in urine is described. Nickel is a normal constituent of most articles of food and between 0.01 and 0.03 p.p.m. are found in normal urine. There is a slight increase of urinary nickel in workers engaged in the carbonyl process. After accidental inhalation of nickel carbonyl, urinary nickel increased in a few hours and reached a maximum about the fourth day, returning to normal in 10 to 14 days. Although an increase of urinary nickel gives an indication of nickel carbonyl absorption, clinical signs and symptoms remain the best guide of the severity of poisoning.
\end{abstract}

The carbonyl process for the production of pure nickel was discovered by Langer and Quincke in 1889. In recent years the uses of nickel carbonyl gas have extended to the manufacture of acrylic esters, catalysts and to the splitting of oils.

One of the main difficulties when dealing with nickel carbonyl poisoning is the existence of both an immediate and a delayed reaction. Clinical symptoms and a knowledge of the nickel content of the blood and urine help to establish the diagnosis. An increase of nickel in the urine furnishes proof of absorption, but no quantitative relationship to clinical symptoms has been established.

Former methods of urine analysis were too complex to be of practical value. The simplified method now described makes use of the fact that dimethylglyoxime precipitates nickel in neutral or ammoniacal solutions; this precipitate is so soluble in chloroform that small amounts of nickel can be completely extracted from aqueous solutions. This chloroform extract, when treated with hydrochloric acid returns the nickel to the aqueous phase where it can be determined colorimetrically. The method is a modified form of that described by Sandell (1944).

Reagents Required:

\section{Method}

(a) Ammonium citrate solution. $-500 \mathrm{ml}$. ammonium hydroxide (S.G. 0.88) is added to $500 \mathrm{~g}$. citric acid until solution is complete, and made up to one litre with water.

(b) Ammoniacal dimethylgloxime. -1 g. dimethylglyoxime is dissolved in $500 \mathrm{ml}$. of ammonium hydroxide (S.G. 0.88) and made up to 1 litre with distilled water. (c) N/10 iodine solution. - Weigh out $12 \cdot 7 \mathrm{~g}$. powdered purest resublimed iodine into a litre flask. Add $20 \mathrm{~g}$. of pure potassium iodide and $200 \mathrm{ml}$. water; shake until the iodine is dissolved. Make up to a litre. Keep well stoppered and in the dark.

(d) Ammonia.-(i) Concentrated ammonia (S.G. 0.88), (ii) $28 \%$ ammonia.

(e) Concentrated hydrochloric acid.

(f) N/10 hydrochloric acid.

(g) Bromine water.

(h) Nickel.-Standard solution-1.137 g. $\mathrm{NiSO}_{4} 6 \mathrm{H}_{2} \mathrm{O}$ $\left(22 \cdot 3 \%\right.$ nickel) per $2 \frac{1}{2}$ litres equivalent to $100 \mathrm{mg}$. $/ \mathrm{l}$. or 100 p.p.m.

(i) Calcium acetate solution- $44 \mathrm{~g} . / \mathrm{l}$.

Short range $p \mathrm{H}$ papers are used for $p \mathrm{H}$ determinations.

\section{Method:}

(1) Removal of Phosphates.-Nickel is incompletely recovered from urine when phosphates are present. Removal of phosphates by the method suggested by Darbey (1952) allows complete recovery of added nickel.

Take $50 \mathrm{ml}$. of urine, add $1.5 \mathrm{ml}$. of calcium acetate solution and $5 \mathrm{ml}$. ammonia (28\%). Shake, allow to stand for five minutes, then filter. This separates the phosphates.

(2) Destruction of Chelate.-When calcium disodium versenate and potassium dithio-oxalate C.P., have been used for the treatment of nickel carbonyl poisoning, the urinary nickel must be released from the chelate complex before estimation.

Make the filtrate from (1) above, $p \mathrm{H} 1$ with $\mathrm{HCl}$, allow it to stand for about $10 \mathrm{~min}$.; this releases the nickel from the chelate complex.

(3) Extraction of Nickel.-Make ammoniacal with concentrated ammonia to about $p H 8$; add $2 \mathrm{ml}$. of ammoniacal dimethyglyoxime and shake for two minutes, 
then add $2 \mathrm{ml}$. chloroform and repeat shaking. Allow to stand, then run off chloroform layer into centrifuge tube.

Centrifuge: Remove any urine remaining on top of the chloroform layer, using a suction apparatus. Repeat the chloroform extraction and add this extract to previous extraction.

Shake the chloroform extract with abcut $1 \mathrm{ml}$. N/10 $\mathrm{HCl}$, making certain the solution is acid, and centrifuge. Remove the top acid layer to a separate tube; repeat this process adding the second acid layer to the previous one.

To this acid solution is now added one drop of $N / 10$ iodine. At this stage a few drops of ammonium citrate solution are added to prevent interference by iron, as shown in Table 1. If the iron is complexed with citrate, interference is prevented and a correct estimation of nickel is made.

TABLE 1

THE EFFECT OF IRON ON NICKEL ESTIMATIONS AND ITS PREVENTION BY THE ADDITION OF AMMONIUM CITRATE

\begin{tabular}{l|c|c|c}
\hline $\begin{array}{c}\text { Iron } \\
\text { Added } \\
\text { (mg.) }\end{array}$ & $\begin{array}{c}\text { Ammonium } \\
\text { Citrate } \\
\text { Solution (ml.) }\end{array}$ & $\begin{array}{c}\text { Nickel } \\
\text { Added } \\
\text { (mg.) }\end{array}$ & $\begin{array}{c}\text { Nickel } \\
\text { Found } \\
\text { (mg.) }\end{array}$ \\
\hline $\mathbf{0 . 0 0 8}$ & - & 0.005 & $\mathbf{0 . 0 0 5 8}$ \\
$\mathbf{0 . 0 1 6}$ & - & 0.005 & $\mathbf{0 . 0 0 6 2}$ \\
$\mathbf{0 . 0 3 2}$ & - & 0.005 & $\mathbf{0 . 0 0 7 0}$ \\
$\mathbf{0 . 4}$ & -5.5 & $\mathbf{0 . 0 0 5}$ & $\mathbf{0 . 0 0 7 2}$ \\
$\mathbf{0 . 0 0 8}$ & 0.5 & $\mathbf{0 . 0 0 5}$ & $\mathbf{0 . 0 0 4 9}$ \\
$\mathbf{0 . 0 1 6}$ & 0.005 & $\mathbf{0 . 0 0 5 1}$ \\
$\mathbf{0 . 0 3 2}$ & 0.5 & 0.005 & 0.005 \\
$\mathbf{0 . 4}$ & 0.5 & 0.005 & 0.0047 \\
\hline
\end{tabular}

Decolourize with concentrated ammonia to $p \mathbf{H} 9$.

Add about $1 \mathrm{ml}$. of ammoniacal dimethylgloxime, shake, cool, then make up to $5 \mathrm{ml}$. If the solution is turbid, filter. If nickel is present the colour intensity increases slowly with time so that readings should be made within 15 minutes.

Measurements are made with a Hilger absorptiometer using a Kodak 1 filter with a tungsten filament lamp. As the effective band width of light is considerable, the calibration graph is slightly curved.

\section{Nickel Content in Human Urine}

Persons Not Engaged in the Nickel Industry.Nickel is present in almost all foods and after digestion is eventually excreted in the urine.

In some countries nickel utensils are widely used for cooking and various investigations have been carried out to determine whether the amounts of nickel absorbed could give rise to toxic symptoms. Drinker, Fairhall, Ray, and Drinker (1924) concluded that the maximum concentrations of nickel found in the urine in these circumstances were too low to be a possible source of kidney damage.

For the nickel content of the urine of people not concerned in any way with the nickel industry, Ghiringhelli and Dakli (1956) give a figure of 0.03-0.09 p.p.m. with a mean of 0.05. Sorinson, Kornilova, and Artemeva (1958) report a figure of between 0.03 and 0.1 p.p.m. Kincaid, Stanley,
Beckworth, and Sunderman (1956) record a grou of 69 unexposed persons with a value of 0.011 p.p (S.D. \pm 0.009$)$. From these data it may be cu: cluded that only one specimen in $\mathbf{5 0}$ selected from a normal population will be found to exceed a value for nickel in urine of 0.03 p.p.m. and this has, therefore, been selected as the upper limit of normal.

Tompsett and Fitzpatrick (1950), whilst estimating the amounts of metal in the urines of shipbreakers and others not engaged in this industry, found an average of 0.029 p.p.m. nickel in the urine, and $8 \cdot 3 \mathrm{mg}$. nickel per $100 \mathrm{~g}$. dried faeces.

I estimated the nickel content in the urines of applicants for employment aged 18 to 48 and found the average to be 0.04 p.p.m. with a standard deviation of $\pm \mathbf{0 . 0 2}$.

Persons Engaged in the Nickel Industry.Ghiringhelli and Dakli (1956) noted that the average nickel content in the urines of 14 men, who had worked near nickel carbonyl for 180 days before scrupulous observance of safety arrangements on the part of the personnel engaged, was 0.365 p.p.m. When the safety arrangements were more strictly observed, the average fell to 0.276 p.p.m.

Sorinson et al. (1958) determined the nickel concentration in the blood and urine of 62 workers before and after one and a half years' work in a new plant using nickel carbonyl. Urine values of 0.67 , 0.8 or even 1.78 p.p.m. were reached, representing an increase several times above the upper limit of normal. These high values of nickel in urine were only found in workers in the principal production departments. No toxic effects were observed. In workers employed in ancillary departments, the nickel content in urine did not exceed 0.05 p.p.m.

Sorinson et al. also noted that the nickel content in urine increased by 0.094 p.p.m. by the end of the shift. They concluded that frequent determinations of nickel in urine should be made in order to reduce the health hazards in all departments of nickel carbonyl production.

I have carried out periodic medical examinations of all men employed in the industry with special regard to the nickel content of their urines. The following results give the average amounts of nickel found in the urine of men working in the various processes: (a) Men engaged in departments where nickel carbonyl is produced and used-between 0.008 and 0.15 p.p.m. was found; (b) Men in departments where no carbonyl is produced or used but where the raw material is smelted or chemically precipitated: (i) Furnaces-between 0.01 and 0.043 p.p.m., (ii) Chemical precipitation plantsbetween 0.005 and 0.06 p.p.m., (iii) Calcination plant-between 0.002 and 0.05 p.p.m. 
Inhalation of Nickel Carbonyl.-After the inzlation of nickel carbonyl gas, nickel soon appears the blood and later in the urine and faeces. wayer (1939) found 52 and 400 micrograms of nickel respectively in the bladder urine of two men who had died a few days after poisoning, In another case Bayer found 3.9 p.p.m., and in a fatal case 0.13 p.p.m. Sunderman and Kincaid (1954) state that the average concentration in 13 cases of poisoning on the fifth day after exposure was 0.17 p.p.m. They also reported on 36 persons accidentally exposed to the vapours of nickel carbonyl, of whom two died and many were critically ill. The nickel concentrations in urine and blood were increased many times above normal after exposure.

Tedeschi and Sunderman (1957) carried out nickel balance studies on normal dogs. These showed that $90 \%$ of the ingested nickel was excreted in the faeces and $10 \%$ in the urine. After exposure to the vapours of nickel carbonyl, the amount of nickel excreted in the urine was strikingly increased. No such increase was found in the faeces.

In rabbits exposed to nickel carbonyl, Armit (1907) found that $75 \%$ of the nickel was excreted in the urine. The rate of elimination was irregular, and reached its maximum on the fourth or fifth day.

Sorinson (1957) reports that a patient undergoing a routine examination showed a normal nickel content of $0.11 \mathrm{mg} . / 100 \mathrm{ml}$. in blood and 0.036 p.p.m. in urine the day before an accident. On the third day after exposure, there was $0.82 \mathrm{mg} . / 100 \mathrm{ml}$. in blood and 1 p.p.m. in urine.

Sorinson et al. (1958) report that the nickel content in urine in cases of acute poisoning during the first three days varied from $0 \cdot 14-1 \cdot 023$ p.p.m.

In cases of nickel carbonyl poisoning, Ceresa (1947) found that nickel was present in the urine after 24 hours, then diminished until the fourth day, started to rise on the fifth day, but returned to normal on the eighth day.

Men under my care who are working on the production of carbonyl have been instructed that if they suffer from a headache or think that they have been exposed to the gas, they must report immediately to the medical department for precautionary treatment. They are put to bed and oxygen therapy is started. Samples of blood are taken for the nickel and carbon monoxide content, and urine samples are taken later. These figures are compared with the amount found during routine examinations; an increase, together with clinical signs and symptoms indicates inhalation of the gas.

Data from 23 cases of accidental exposure are presented in Tables 2 and 3.

TABLE 2

NICKEL IN URINE AFTER INHALATION OF NICKEL CARBONYL (MEN WHO DID NOT REPORT IMMEDIATELY AND WHO LOST TIME)

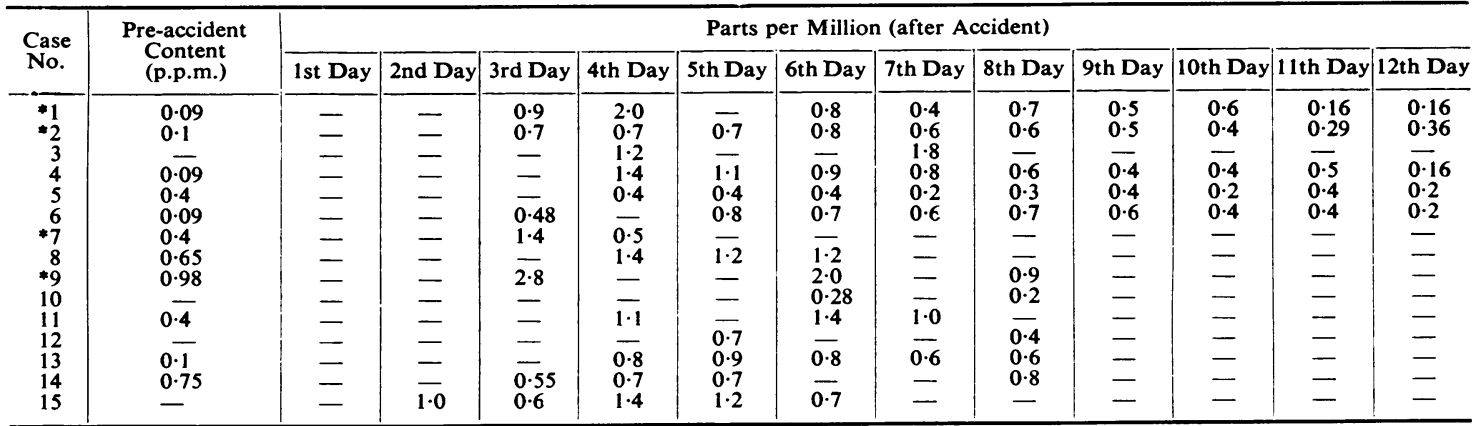

*Admitted to hospital.

Case No. 1.- In hospital for seven days; temperature $101^{\circ}$ for four days returning to normal from the fifth day. Pulse varied between 110 per min. and 70 per min. Respirations varied from 35 per min. to 25 per min. returning to normal by the seventh day. Pulse respiration ratio $1: 3$ to $1: 4$. Blood pressure $130 / 80$. Urine output averaged $30 \mathrm{oz}$. daily for first few days, then 60 oz. daily by discharge date. Uneventful recovery.

Case No. 2. - In hospital for six days. Temperature varied from $103^{\circ}-100^{\circ}$ returning to normal on sixth day. Pulse varied from $130-90$ per min. returning to 70 on the sixth day. Respirations varied between 52-30 per min., returning to normal on the sixth day. Pulse respiration ratio $1: 2$ to $1: 3$. Blood pressure 150/100, falling to $120 / 90$ by the third day. Uneventful recovery.

Case No. 7.- In hospital for seven days. Temperature $102^{\circ}$ for three days returning to normal on the sixth day. Pulse varied from 135 to 90 per min. for four days, returning to normal on the fifth day. Respirations 45 per min. for four days, then returned to normal Pulse respiration ratio $1: 3$ to $1: 4$. Blood pressure 148/90. Urine output averaged 30 oz. daily for first five days then 55 oz. daily. Dyspnoea on exertion for about one month, then full recovery.

Case No. 9.- In hospital for seven days. Temperature $103^{\circ}$ returning to normal on the fourth day. Pulse 120 per min. for two days, 100 mer min for two days, then normal. Respirations varied between 35-25 for five days then returned to normal. Pulse respiration ratio $1: 3+$. Urine output averaged $52 \mathrm{oz}$. daily for first two days, then $36 \mathrm{oz}$. for one day only, then returned to $64 \mathrm{oz}$. daily.

Two $0.5 \mathrm{~g}$. calcium disodium versenate tablets were given daily to each of the above men for four days, commencing three days after the inhalation. 
TABLE 3

NICKEL IN URINE AFTER INHALATION OF NICKEL CARBONYL (MEN WHO REPORTED IMMEDIATELY AND WHO LOST NO TIME)

\begin{tabular}{|c|c|c|c|c|c|c|c|c|c|c|c|c|c|}
\hline \multirow{2}{*}{$\begin{array}{l}\text { Case } \\
\text { No. }\end{array}$} & \multirow{2}{*}{$\begin{array}{l}\text { Pre-accident } \\
\text { Content } \\
\text { (p.p.m.) }\end{array}$} & \multicolumn{12}{|c|}{ Parts per Million (after Accident) } \\
\hline & & Ist Day & 2nd Day & 3rd Day & 4th Day & 5th Day & 6th Day & 7 th Day & 8th Day & 9th Day & 10th Day & 11 th Day & 12th Day \\
\hline $\begin{array}{l}16 \\
17 \\
18 \\
19 \\
20 \\
21 \\
22 \\
23\end{array}$ & $\begin{array}{l}E \\
\overline{0} \cdot 11 \\
\bar{Z} \\
\bar{Z}\end{array}$ & $\begin{array}{l}1.0 \\
0.38 \\
0.1 \\
0.3 \\
0.4 \\
1.3 \\
0.8 \\
0.7\end{array}$ & $\begin{array}{l}1 \cdot 2 \\
2 \cdot 0 \\
0 \cdot 2 \\
- \\
2.9 \\
1 \cdot 4 \\
-\end{array}$ & $\begin{array}{l}= \\
= \\
= \\
=\end{array}$ & $\begin{array}{l}E \\
z \\
z \\
-\end{array}$ & $\begin{array}{l}= \\
= \\
\bar{z} \\
=\end{array}$ & $\begin{array}{l}0.2 \\
0.3 \\
0.2 \\
0.4 \\
0.8 \\
0.4 \\
-\end{array}$ & $\begin{array}{l}0.15 \\
0.4 \\
0.2 \\
0.5 \\
\overline{0.8} \\
- \\
-\end{array}$ & $\begin{array}{l}0.2 \\
0.2 \\
0.15 \\
0.9 \\
\overline{0.8} \\
\overline{0.2}\end{array}$ & $\begin{array}{l}0.2 \\
0.2 \\
0.2 \\
0.9 \\
- \\
1.0 \\
-\end{array}$ & $\begin{array}{l}E \\
E \\
E \\
E\end{array}$ & $\begin{array}{l}E \\
E \\
= \\
=\end{array}$ & $\begin{array}{l}- \\
E \\
E \\
-\end{array}$ \\
\hline
\end{tabular}

Two $0.5 \mathrm{~g}$. tablets of calcium disodium versenate were given daily for two days to each of the above men.

These Tables show that an increase of nickel occurs in the urine a few hours after inhalation and increases until it reaches its maximum about the fourth day, gradually diminishing until it returns to normal about the 10th to 14th day.

An increase of nickel in the urine can only be used as an indication of nickel carbonyl poisoning and not as a measure of the severity of the case. Clinical signs and symptoms are the best guide to severity.

I should like to express my thanks to my staff for their help in this work.

\section{REFERENCES}

Armit, H. W. (1907). J. Hyg. (Camb.), 7, 525.

Bayer, O (1939). Arch. Gewerbepath. Gewerbehyg., 9, 592

Ceresa, C. (1947). Med. A. Lavoro, 38, 225.

Darbey, A. (1952). Analyt. Chem., 24, 373.

Drinker, K. R., Fairhall, L. T., Ray, G. B., and Drinker, C. K. (1924). J. industr. Hyg., 6, 307.

Ghiringhelli, L., and Dakli, I. (1956). Med. d. Lavoro, 47, 340.

Kincaid, J. F., Stanley, E. L., Beckworth, C. H., and Sunderman, F. W. (1956). Amer. J. clin. Path., 26, 107.

Sandell, E. B. (1944). Colorimetric Determination of Traces of Metals, p. 339. Interscience Publishers, New York.

Sorinson, S. N (1957). Gig. $i$ Sanit, 22, No 11, 30

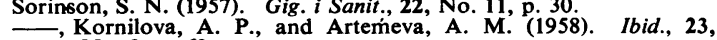
No. 9, p. 69 .

Sunderman, F, W., and Kincaid, J. F. (1954). J. Amer. med. Ass., $155,889$.

Tedeschi, R. E., and Sunderman, F. W. (1957). A.M.A. Arch. industr. Hlth, 16, 486.

Tompsett, S. L., and Fitzpatrick, J. (1950). Analyst, 75, 279. 